\title{
The Pragmatics of Email Request between Iraqi Students and English Native Speakers
}

\author{
Dr. Raad Hameed Kambash \\ Al-Nisour University College, Iraq
}

Doi: 10.19044/llc.v7no1a1

URL:http://dx.doi.org/10.19044/llc.v7no1a1

\begin{abstract}
Communication via email between Iraqi students and English tutors has been increased in recently since the large number of Iraqi scholarships to the UK as well as the opportunities for distance learning. Although it has not yet done better than the use of face-to-face communication (office hours), email message is already used more frequently than by phone for student to faculty and faculty to student communication. When communicating with native speakers via email messages most non-native speakers have a pragmatic failure in using their competence. Personally, I have been asked so many times by Iraqi students to assist them in writing email messages that I noticed the pragmatic failure of those students. However, little is examined about the pragmatics of Iraqi email writing. So, this paper is an attempt to fill this gap by highlighting the pragmatics of written discourse on the behalf of Iraqi students to English native speakers via emails. I intend to investigate how Iraqi students use their linguistic and nonlinguistic competence, principles of (in)formality and (in) directness in their communication via email messages.
\end{abstract}

Keywords: Pragmatics, Iraqi Students.

\section{Introduction}

It is clearly seen from this study that Iraqi learners differ from native speakers in politeness, illocutionary and perlocutionary act. It has also been concluded that both native and non-native speakers use different strategies in order to convey their intended message. Such strategies are of those which relate to the form and content used in their email requests. Through this study, it is highly recommended to assume a pedagogical model in order for second language learners to send email requests appropriately and to show the promising benefits of such a model. Moreover, Communication via email is an ideal way used by nonnative speakers so that they might improve their English. Therefore; this paper also provides some suggestions for writing email messages. 


\section{Intercultural communication}

Language has a twofold character as a means of communication and a reflection of culture. Language without culture is a meaningless language, so is human culture without language. A particular language is a mirror of a particular culture. Kramsch (2009: 69-70) maintains that language is a part of a culture and a culture is a part of a language; the two are intricately blended so that one cannot separate the two without losing the significance of either language or culture.

Culture and language are inseparable, and culture is the foundation of any linguistic communication, and diverse cultural backgrounds influence communication in subtle and profound ways. Speakers' familiarity with the pragmatic norms and rules of a particular language either written or spoken and culture is highly essential for successful intercultural communication. The researcher is going to shed some light on Intercultural communication and how it affects communication between people.

Intercultural communication (Henceforth IC) refers to different societies and communities in which people from different linguistic and cultural backgrounds speak differently., The speakers' different ways of communication can be clarified and understood in terms of independently established different cultural values and cultural priorities. Lustig \& Koester (2003: 49-51) define IC as a "symbolic process in which people from different cultures create shared meanings". In addition, they show that IC takes place "when large and important cultural differences create dissimilar interpretations and expectations about how to communicate competently". Communication between people from different cultures could be influenced by the different mental knowledge they have. In some cultures, for instance, people usually offer coffee directly after a meal which is generally known as a respectful way to show to their guests that they have to leave as soon as possible in case they do not wish to overstay their welcome. In other cultures, an offer of coffee in a similar context is just a performance of the people's gentleness or even a request to the guests to stay longer. If the interlocutors from different cultures are unaware of their cultural background differences, misunderstanding is likely to occur in their languages, behaviour or even feeling (Pennington, 2010:2).

\section{Pragmatic Competence and Pragmatic failure:}

Pragmatic competence is the speaker's ability to perform social functions which has been recognized as a central part of the second language communicative competence. As proposed by Cohen (1996:22), any learner has pragmatic competence which, in turns, has two interrelated components: sociocultural and sociolinguistic. Each one of these is concerned with regulating certain abilities. The former refers to the speaker's skill or ability 
which is used to choose speech act strategies within appropriate context including the age and sex of the interlocutors, their social statue and their role in interaction. The latter indicates the respondent's skills or abilities to select appropriate linguistic forms and structures to express the illocution of the speech act. These two communicative competences; "sociocultural and sociolinguistic" are going be observed through examining the email messages sent by Iraqi students.

For learning a target language appropriately, it is vital for second language learners to develop their awareness of the pragmatic norms that relate to the target language. They are required to understand, recognize and learn to interact in different situations depending upon their communicative aims. In addition, being familiar with cultural norms is a great help in successful communication (Cohen1996; Kasper and Rose 2002). Pragmatic transfer can also be defined as the influence of a person's first language on speech acts realized in the target language. Under the scope of interlanguage pragmatics, this concept involves the influence of the second language learners' knowledge of their languages. Thus, the popularity of pragmatic transfer as an explanatory concept in research relies on two assumptions: firstly, the production and comprehension of certain linguistic expressions is largely affected by learners' first language pragmatic knowledge; secondly, learners' pragmatic transfer is often caused by their returning to first language pragmatic norms (Kasper, 1992:207).

Since this research is concerned with the pragmatics of email request by non native speakers, the next section focuses on communication via email. It therefore, sheds light on some aspects of email conventions and provides an account of netiquette or and polite expressions used to convey the illocutionary act of request.

\subsection{Request: Definitions and Strategies}

The speech act of request is a category of directives speech act which make the addressee to do certain action which is for the benefit of the speaker, for instance, could you pass me the salt? May I meet you tomorrow, could you read my paper? etc. (Trosborg,1995). The speech act of request has also been considered as the most threatening speech act since it is basically threatening the addressee's face (Brown and Levinson, 1987).

A large number of research on both interlanguage and cross cultural pragmatic have been devoted to examine request. In both fields, native and non native speakers find themselves making requests frequently. In interlanguage pragmatics, as discussed in the section of previous studies, non native speakers face a difficulty in performing a request because of their sociocultural background. 
Blum-Kulka and Kasper (1989) state that the act of request can be performed by different strategies. These strategies are classified into some types:

(a) The head act which is the main illocutionary act of the utterance:

(b) alerters which can function as an attention drawer. They include: Titles such as (Dr. Prof. Sir. Mr. ...etc), Last name and first name, nicknames, personal pronouns, expressions of endearments or offensive, expression of apology such as 'excuse me'.

(c) Supportive moves which are used to moderate or exaggerate requests. These can be used either before or after the head act 'request' and include precommitment, explanations, giving reasons, promising, minimizing the imposition, moralizing signs,

(d) Internal Modifications which can be used within the head act 'request' and accompanied with syntactic downgrades such as 'could' instead of 'can' and 'would' instead of verb to 'be', for instance, 'would it be possible?' instead of ' is it possible? and lexical downgrades for example, , possibly Please, just'.

\section{Communication via Email (email Convention)}

With the advent of the internet, communication via email messages has become an increasingly widespread means of contact and interaction within the academic environment. Email interaction, whichhas replaced face to face interaction, phone calls and other forms of written messages, has become central channel in dealing and interaction between students, their lecturers, supervisors and academic staff in general. Students usually send emails to their lecturers or supervisors in order to make requests for meeting, for feedback, a proofreading, a letter of recommendation, or a deadline extension (Taylor et al., 2011).

Crystal (2001) states that email communication is viewed as the principal instance of the huge increase of informalization of speech. However, crafting appropriate email messages requires pragmatic competence of nonnative speakers which, in turns, has two interrelated components: sociocultural and sociolinguistic, as well as for native speakers to adjust language to a new context that has no specific rules for the way in which student can communicate with his/her tutor appropriately.

Through her book "netiquette", Shea (1994) presents principles, rules and guidelines for communication via online in general and she describes in particular, the sociocultural rules of interaction via email. For example, one should keep to the same values of behavior online that he follows in real life. She adds that Netiquette differs from one area to another. Therefore, the etiquette of communication may differ depending on the environment, what's acceptable in one context may be really offensive in another. 
Some studies have been conducted to establish strategies and guiding principles for an appropriate email behavior. Emily Post's Etiquette (2011) includes a complete chapter for communication via email. It has been shown that the main principle for electronic communication is that you should treat others as you would have them treat you" (240). This is followed by more specific rules of electronic communication. These rules can be summarized as follows:

a) Be careful about what you say and how you say it.

b) Address with care

c) What's the main subject?

d) Make your subject short and ordered.

e) Avoid capital letters except for close friends and family members

f) Avoid offensive words

g) Check the subject before sending.

h) Send individual email rather than in a group

In one word, Emily Post Etiquette states that communication via email is an important, but is not a replacement for the personal interaction. Instead, using email should be carefully employed since it is naturally impersonal; users often exceed the good behaviors that they would use in the face to face interactions (238-242).

Perez-Sabater(2011) addresses the different styles of writing messages via email. He discussed the formality and informality of emails. For academic or special purposes, there has been an increasing development in the usage of email messages as a means of interaction in different contexts. Concerning the opening and closing expressions, they are likely to be different depending on the conventions of the sender or the receiver. He categorized greetings and sign-offs or farewell as follows:

1-Dear $\mathrm{Dr} / \mathrm{Mr}+2^{\text {nd }}$ Name $\rightarrow$ very formal

2-Dear $+1^{\text {st }}$ Name $\rightarrow$ formal

3-Hello+ Name $\rightarrow$ informal

4-Hey, Hi or +name $\rightarrow$ very informal

5 -Yours, Sincerely $\rightarrow$ very formal

6-Best wishes, Regards $\rightarrow$ informal

7-Cheers, kisses, bye $\rightarrow$ very informal

Swales and Feak (2004: 308-309) state that many international students' email messages include overused opening and closing conversational style adopted from phone conversations. Consider the pragmatic mistakes found in the following example:

Hi Chris ! How are you? This is Fatima from your 321

class. Can I change our appointment to Friday at 9:30? I

have a test on Wednesday. Have a good day.

Got to run. Bye, bye, Fatima. 
The language used in writing email messages is normally informal and it is convenient for nonnative speakers so that they cannot worry about errors and ill formed sentences. However, difficulties may occur as a result of such informality when nonnative speakers send a request by using direct speech act to their tutors or supervisors or academic staff in general. Using too directness is deemed to impoliteness in an academic context.
a)Avoid imposition
b)Giving options
c)Make the reader/ receiver feel good
d)Be clear and brief
e)Avoid emoticons

\section{Previous Studies}

Over the past decade, second language learners have become more interested in using emails texts. Early research and studies have been conducted to reveal the effective usage of emails in academic and educational situations. In addition, such studies seek to reveal both the function and form of email texts and what type of implicature that could be deduced from them (John \& Cash, 1995; Gaines, 1999; Lan, 2000). Noriaen reveals the significance of learning via email dialogues about writing skill of ESL learner at the University of Malaysia Terengganu. Her revision shows that it is very important to use a modest email as a device to recruit discussion among students who wish to develop their writing that leads to positive effect even though few mistakes occur. Another survey made by Lain(2000) who investigates e-mail messages emailed between a university in England and another in Hong Kong and he stated that both NSs and NNSs of English in both contexts use formal, semi-formal and polite emails but with fluctuating degrees of pragmatic strategies. Such a research implies that different pragmatic strategies are necessary for successful communication in different situations for different objectives. Bloch (2002) examines e-mail messages from international students to their tutors by first categorizing the messages for communication topics according to the purpose. Some messages were categorized as asking for help, formal request and making excuses. Furthermore, the rhetorical strategies used by those students were examined and identified. The results of that study showed that depending on the degree of convention of the environment, there are no problems in using the required strategies.

In another study, Najeeb, Maros and Nor (2012) investigated crosscultural differences among Arab students who were studying in Malaysia as international students. In this study researchers analyzed emails that were sent by Arab students to their supervisors. The results showed that Arab students applied different politeness strategies, and were more direct in their requests. 
Arab students had some problems during their studies in Malaysia, one of which was lack of fluency in English and another problem was lack of knowing sociolinguistic and pragmatics norms sufficiently in email writing. "While certain ways of expressions would be acceptable in the Arabic language, they may be considered as impolite or unacceptable by their Malaysian supervisors communicating in English" (Najeeb, Maro \& Nor, 2012, p.127). Thus, students should be aware of socioliguistics and sociopragmatics norms in order to have effective and appropriate email communication in cyber space. The other important factor is that politeness strategies may vary in different cultures (Najeeb, Maros \& Nor, 2012).

Ford (2003) discusses the pragmatic differences in various subject groups of study and shows the nature of those differences performed by NS and NNS speakers with different levels of English language skill and university education experience. He concluded that there is a difference in the pragmatic usage of emails texts; and these differences lie in some features. These features include (a) obligatory formal features (e.g., subject heading, greeting, closing),(b)non-obligatory formal features (e.g., emotive questions), (c)particular request (e.g., conditionals), modals, (d) politeness features (e.g., downtoners), (e) justifying supportive moves (e.g., preparators, grounders, thanks).

In her study, Biesenbach-Lucas (2005) investigates the pragmatics of American and international students' e-mail messages. In this study she classifies their communication topics into (a) facilitative, (b) substantive and (c) relational and their strategies into (a) requesting, (b) negotiating and (c) reporting). She concluded that both speakers addressed facilitative, rational and substantive topics, but they were different in the frequency of their email messages. American students sent more facilitative and substantive emails while emails from international students contained more relational topics. Hartford and Bardovi-Harlig (1996) claim that both facilitative and substantive topics are appropriate to be included in e-mail messages to professors. Biesenbach-Lucas (2005) states that the large number of email messages with relational topics can be assigned to the fact that the absence of body language calls for verbal return. In what concerns the strategies, the all three strategies have been used in different ratios by the American students. Regarding requesting, for instance, they sent a high percentage of messages which include explicit response category. Supporting this behavior, the author (2005) asserts that:

"If a student wants to increase the chances that his or her message is responded to, the student has to encode this request explicitly, leaving the professor no choice but to respond.... However, this is also far more risky as appropriate linguistic realizations for these requests have to be chosen that do not come across as inappropriately impolite and imposing (p.40)". 
Then, Waldvogel (2007) investigates the use and form of greetings and closing in the emails of an educational setting and manufacturing plants in New Zealand. She concluded that workplace culture has a great impact on the expressions of greetings and closing.

In conclusion, communication via email is not the only way, but instead it is a new medium. Although it nature is still vague, attempts have been made for setting new rules and conventions of polite behavior via internet. For nonnative speakers, they are challenged by their pragmatic transfer when involving an interaction between their pragmatic knowledge and skills acquired or inherited from other cultures. Thus, in our data analysis we are going to focus on the expressions of formality/ informality, directness/indirectness as well as the students' strategies for making an email request.

\section{Research Methodology}

In this research, I investigate the pragmatic characteristics of e-mail request written in English by Iraqi students whose major is not English to their professors at British Universities. This paper aims to answer the following questions:

1. What communication strategies do the IPS use to communicate?

2. What politeness strategies do they use?

3. To what extent do they use the (in)directness and (in)formality in their emails?

\section{The Subjects and Method}

In order to gain natural data for this research, some Iraqi students have been requested to forward to the researcher at least three email request sent lately to their tutors. 50 emails were collected from Iraqi students in different universities in the UK. Email requests collected by this way can be regarded as naturally occurring data since the students might possibly formulated and sent their emails when they were not being observed by others. Background information has been collected from the participants about their education background, how long they been in the UK, ever lived abroad, how long, gender, age. For ethical considerations, the name of the sender and the recipient were hidden.

\section{Data Analysis}

Brown and Levinson's model of politeness is one of the models that try to explain how people produce and perceive politeness. I have chosen this model since it considers politeness in a reasonable manner and pays attention to the various strategies we use to create politeness. Brown and Levinson view politeness as the product of people's strategies sprung from the rational 
orientation. There may be social controls or constraints that shape people's linguistic behavior, but Brown and Levinson deal with social factors as variables that affect the speech act.

The collected data in the present study are coded into semantic formula and then are a degree of reliability was established through descriptive analysis. It is noted that frequencies of using strategies of request by the two groups namely long time EFL learners' residency in the UK and short EFL learners' residency in the UK.

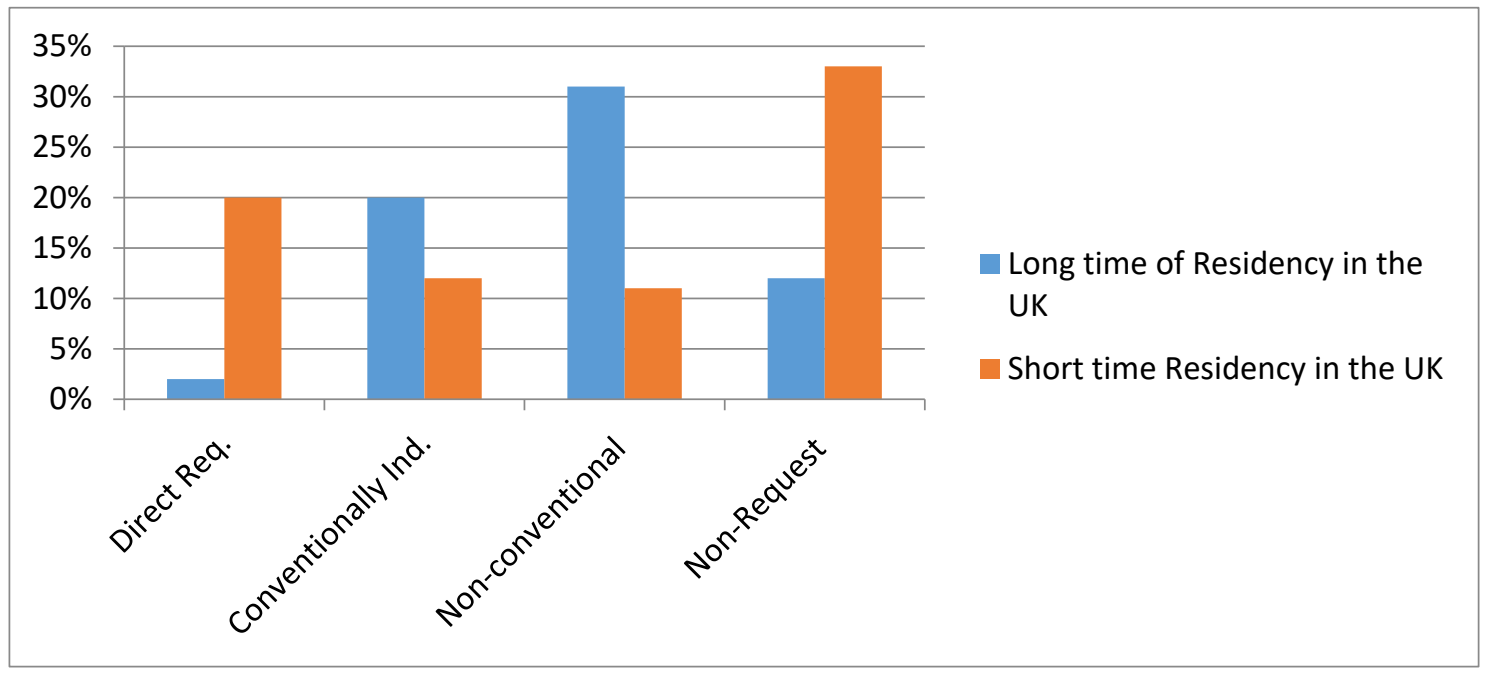

The relationship between the sender and the receiver is high 'supervisor and student' or on occasion it is supposed to be less distant between the student and an administration employer. However, there has been a variety of request strategies used by the two groups.

First, the two groups of email request involved direct strategies. The employment of direct strategies by the EFL learners in their mother land is most probably due to the less familiarity between the students and their supervisors. However, the choice of conventional request used by the residents in the UK [example] is due to the nature of request as face threatening act because asking for something from the supervisor, is however an easy, indicate the a degree of politeness. This could be assigned to the cultural affect that they acquired while living in the UK. The request speech act was perceived as face threatening act or imposing act by the Iraqi EFL learners in spite of the fact that they are familiar with their supervisors and they should contact them by sending emails.

Secondly, the conventionally indirect request was the most strategy that is found in the two emails groups under investigation. Thus, nonfamiliarity and online communication between the interlocutors with the 
receiver's minimum obligation to accept the requester's email might affect the sender's requestive speech act behaviour. The conventionality of request used by the two groups shows their carefulness to reflect their politeness as an attempt to accept the student's proposal, the student's excuse for not turning up to a meeting.

On the other hand, it has been noted that there was no request which we labeled it as non-request strategy. It is the second most frequent strategy used by those who are not living in the UK [33\%]. The average of non-request strategy for EFL learners resident in the UK was $12 \%$. Instead of making request, they used orders, want statements, wishing statement rather than making request. The analysis of the results shows that a variation of different strategies used by the two groups. There has been similarity and differences, but in total the similarities were more than differences. The majority of requesters have inclined to use conventional request strategies rather than using direct requests.

(1) From a student A to academic staff Dear Sir/Madam

1. I want a confirmation letter directed to my sponsor take in consideration the following points:

Fees of study

Subject of study

The period to finish my $\mathrm{PhD}$ study.

Kind Regards,

\section{(2): From a student to his supervisor}

Dear

I wish you are very well, I completed the last draft of paper, I am reduce the number of pages to 7 pages. Please find the attached paper.

Please, you can send your feedback ASAP (your feedback very important to me). I will complete your feedback after that I will send the paper to Prof. (X). We need to submit the paper to the "The 24th International Conference on Computer Communication and Networks (ICCCN 2015)", Deadline February 26. I would like to submit the paper before my BM (confirmation March) that support me. Finally, I think you are busy (I need to inform you about last update).

Many thanks for you

Have a good weekend

3-From a student to Professor

Hello Dear 
I have scholarship I would to work with you after I saw your website. I have M.Sc degree (computer science/ image processing) I would like to complete my $\mathrm{PhD}$ in image processing. I have experience in fractal geometry and texture classification. please find attachment.

Best regards

\section{4-From a student to a supervisor}

Dear Dr. X

please could you find the attachment which is for cores work lab \#1.

kind regards

From a student to academic staff

Dear Sir/ Madam

I want to extend the time to submit the transfer report, because, I have changed lately to new research area. I hope to consider it and I'm continuing in writing my transfer report and I hope to complete it as soon as possible.

Kind regards

6-From a student to his supervisor

Hi doctor,

I am wondering if you have free time tomorrow morning because I need some explanations about the course work. Could I see you today afternoon please?

\section{Conclusion}

This paper has demonstrated the strategies of making request by the non-native speakers directed to the native speaker by email communication. It has been found that the long term resident at the country of the native language used indirect strategies of request showing their politeness norms whereas direct and conventional request strategies were used by the speakers whose living resident in the UK is short.

It can also be concluded that the small social relationship represented by social distance between the sender and the receiver, the more direct request performed. This can be justified by the fact that familiarity allows the sender or the requester not only to be direct but also to share information and talks based on their experience in certain situations.

Moreover, the short term residents appear not to be motivated by politeness in terms of consideration for the social distance, that is to say the more social distance between the email receiver 'the native speakers', the more direct strategy of making request. 


\section{References:}

1. Bardovi-Harlig, K., \& Hartford, B. S. (1996). Input in an institutional setting. Studies in second language acquisition, 18(2), 171-188.

2. Biesenbach-Lucas, S. (2005). COMMUNICATION TOPICS AND STRATEGIES IN E-MAIL CONSULTATION\&58; COMPARISON BETWEEN AMERICAN AND INTERNATIONAL UNIVERSITY STUDENTS. Language Learning and Technology, 9(2), 24-46.

3. Brown, P., \& Levinson, S. C. (1987). Politeness: Some universals in language usage (Vol. 4). Cambridge university press.

4. Cohen, Andrew D. "Speaking strategies for independent learning: A focus on pragmatic performance." Language learning strategies in independent settings 33 (2008): 119.

5. Kasper, Gabriele, and Kenneth R. Rose. "Pragmatic Development in a Second Language." Language Learning: A Journal of Research in Language Studies 52 (2002): 1.

6. Kasper, Gabriele. "Pragmatic transfer." Interlanguage studies bulletin (Utrecht) 8.3 (1992): 203-231.

7. Kramsch, C. J. (2009). The multilingual subject: What foreign language learners say about their experience and why it matters. Oxford University Press.

8. Lees-Maffei, G. (2012). Small Change?: Emily Post's Etiquette (19222011). Must Read: Rediscovering American Bestsellers.

9. Najeeb, Z. M., Maros, M., \& Nor, N. F. M. (2012). Politeness in emails of Arab students in Malaysia. GEMA Online ${ }^{\circledR}$ Journal of Language Studies, 12(1).

10. Pérez-Sabater, C. A. R. M. E. N., et al. "Active learning to improve long-term knowledge retention." Proceedings of the XII Simposio Internacional de Comunicación Social. 2011.

11. Shea, V. (1994). Core Rules of Netiquette. Educom Review, 29(5), 5862.

12. Swales, J. M., \& Feak, C. B. (2004). Academic writing for graduate students: Essential tasks and skills (Vol. 1). Ann Arbor, MI: University of Michigan Press.

13. Waldvogel, J. (2007). Greetings and closings in workplace email. Journal of Computer-Mediated Communication, 12(2), 456477. 